\title{
Formar formadores para a escrita profissional
}

\author{
Tommaso Raso \\ Universidade Federal de Minas Gerais - UFMG
}

RESUMO: Este trabalho apresenta alguns dos resultados de dez anos de pesquisa e atividade didática para formar formadores de escrita profissional, tanto no sistema educacional quanto no mundo do trabalho. Em particular, apresenta-se um currículo base de competências comuns a todos os formadores, sem distinção de destinação didática. Essas competências são resumíveis em cinco pontos: a consciência da variação entre as estratégias textuais da fala e da escrita; a habilidade em identificar as informações dentro de um contexto e usá-las para os próprios fins textuais; a consciência dos traços que caracterizam um gênero textual e a capacidade de gerenciálos na reformulação para objetivos diferentes; a capacidade de gerenciar os diferentes aspectos de uma situação comunicativa; a argumentação, com e sem documentação. O trabalho privilegia as competências textuais sobre aquelas lingüísticas de superfície e, portanto, mesmo pensado para um ambiente italófono, é aplicável a qualquer língua-cultura ocidental.

PALAVRAS CHAVE: escrita profissional, formação, textualidade.

ABSTRACT: This paper presents some results of a ten year research and teaching project for educating educators for professional writing, either in the educational system or in the working environment. Specifically, it presents a curriculum of basic competences that all educators should have, independently of the didactic destination. These competences can be summarized in five points: the conscience of the variation between speaking and writing textual strategies; the ability to identify information within a context, and in using it for textual purposes; the conscience of the parameters that characterize a textual genre, and the capacity of managing them reformulating a text for different purposes; the skills for managing the different aspects of a communicative situation; and, finally, argumentation, with and without documentation. The study privileges textual rather than surface linguistic competences; so, even if elaborated for an Italian speaking environment, it is applicable in any occidental language and culture.

KEY-WORDS: professional writing, education, textual competence 


\section{Introdução: origem e definição do trabalho}

Apresento aqui alguns dos resultados do trabalho realizado a partir de 1996 pelo "Servizio d'italiano scritto" (SIS) ${ }^{1}$ da universidade de Veneza, coordenado por Francesco Bruni e por mim. O SIS, entre outras coisas, elaborou instrumentos para o ensino da escrita profissional nas diversas faculdades (BRUNI et alii, 1997a; 1997b), nos setores da administração pública (RASO, 1999-2000; 2004; 2005), para o ensino da escrita voltada para a rede Internet (ACERBONI, 2005), para a formação de professores (BRUNI; RASO, 2002a), ${ }^{2}$ e alimentou o debate sobre o assunto fornecendo cursos e consultorias para outras universidades, inclusive estrangeiras, e organizando o primeiro congresso internacional sobre a escrita profissional (COVINO, 2001).

Com a expressão "escrita profissional" se entende a produção textual utilizada para um trabalho específico, não literário, não publicitário e não jornalístico. São, portanto, potenciais destinatários dessas competências alunos do ensino médio e do ensino superior, profissionais liberais, funcionários da administração e da burocracia, de empresas, bancos e organizações não governamentais que utilizem a escrita, em qualquer suporte, inclusive Internet, para fins profissionais. Naturalmente cada destinação didática prevê objetivos, estratégias e competências específicas, mas é possível identificar um núcleo duro que não pode faltar em qualquer formador de escrita profissional, seja ele destinado ao ensino na escola ou na universidade, seja ele interessado na formação dos quadros administrativos ou empresariais.

\footnotetext{
${ }^{1}$ O SIS nasceu, por iniciativa de F. Bruni, no Departamento de Italianística da Universidade de Veneza, Ca' Foscari em 1996. Em princípio, o objetivo era oferecer para os alunos de todas as faculdades cursos de textualidade, ou seja, instrumentos que fornecessem uma maior capacidade de elaboração e redação de textos úteis na vida acadêmica e profissional. Em seguida, o sucesso da iniciativa induziu uma forte demanda por parte de escolas, setores da administração pública, empresas e outras universidades. Isso gerou a necessidade de formar um grande número de docentes que pudessem elaborar e ministrar os cursos. Nos últimos meses de 1999, o SIS organizou um curso de formação de formadores aberto aos doutores ou doutorandos de todas as universidades do Triveneto (Veneza, Verona, Padova, Feltre, Trento, Trieste, Udine). Para uma idéia das atividades realizadas, veja-se o site www.italianoscritto.com.

${ }^{2}$ Raso e Acerboni estão agora trabalhando especificamente sobre a formação nas empresas, depois de quatro anos de atividade de formação destinada aos quadros e aos dirigentes de várias grandes empresas italianas.
} 
O que apresento aqui é exatamente essa base comum, essencial para o formador, independentemente da destinação didática. O destinatário do curso $^{3}$ pode ser tanto um professor do ensino médio quanto um aluno universitário ou o responsável pela formação em uma empresa ou organização profissional. Portanto vou chamá-lo genericamente de aprendiz. O currículo base pode ser identificado em cinco estágios ordenados, que se concretizam na aprendizagem de cinco competências textuais: 1 . a reformulação da fala para a escrita; 2 . o resumo com mudança de corte; 3. a formulação e a reformulação de tipos textuais específicos; 4 . o gerenciamento da situação comunicativa; 5 . a argumentação. Desses estágios, somente o primeiro é totalmente propedêutico aos outros. Os estágios 2-4 podem aparecer, desde que em uma versão claramente simplificada, antes dos sucessivos, mas acham a sua expressão mais completa somente na ordem indicada. Em seguida concentro a minha atenção sobre cada uma dessas etapas, argumento sobre a importância delas no processo formativo, sabendo que elas não completam o perfil de um formador, entretanto tento mostrar o valor propedêutico que elas revestem, e sugiro também exercícios para treiná-las.

Vale ressaltar que não é objetivo do trabalho discutir as diferentes orientações teóricas sobre lingüística de texto, nem tomar posição em relação a elas. Ao contrário, busca-se traduzir sinteticamente em operações didáticas concretas aspectos da reflexão teórica oriundos de tradições diferentes, dando conta, ao longo da exposição, de parte dessas reflexões. ${ }^{4}$ Mesmo assim, duas foram as preocupações presentes com constância no trabalho sintetizado neste artigo: as expectativas que facilitam no destinatário a decodificação e a recepção de um texto, e a eficácia pragmática com que o autor executa a ação que a própria profissão requer. ${ }^{5}$

${ }^{3}$ Obviamente adaptado às circunstâncias, mas sempre baseado, em seu núcleo, nas competências tratadas neste artigo.

${ }^{4}$ A bibliografia sinalizada ao longo da exposição escolhe alguns dos estímulos principais de reflexão que se julgam frutíferos para pautar uma operação didática. Uma atenção maior é reservada a textos da tradição européia menos conhecidos do público brasileiro.

${ }^{5}$ Portanto, mesmo que em pesquisas diferentes por objetivos científicos ou tradições culturais, o que se busca na teoria são contribuições a essas duas preocupações de base. 


\section{A reformulação da fala na escrita}

É notório que a fala e a escrita são duas atividades diferentes, com objetivos e, portanto, estratégias diferentes. ${ }^{6}$ Enfim, qualquer lingüista sabe que usar na escrita os instrumentos eficazes na fala e na fala aqueles prepostos à escrita leva ao insucesso comunicativo. ${ }^{7}$ Mas também é muito comum não achar, nas pessoas que não tenham uma formação lingüística específica, mesmo se cultas e ótimas profissionais, uma plena consciência da variação ligada ao meio de expressão. O que acontece com maior freqüência é que a atividade mais natural e muito mais freqüente, ou seja, a fala, interfira nas estratégias textuais da escrita. Entre os problemas mais graves e mais recorrentes podemos indicar os seguintes:

1. a dificuldade de mudar as coordenadas para se referir aos elementos que constituem a situação comunicativa. Se a fala acontece normalmente in praesentia, ou seja, os interlocutores compartilham o tempo e o espaço quando falam e escutam, na escrita quem escreve e quem fala não interagem em uma situação comunicativa dada. A dêixis, por exemplo, é automaticamente dada na fala (onde expressões como eu, aqui, boje não precisam de maiores explicações), mas necessita de referências preliminares na escrita, onde se transforma em anáfora ou em dêixis textual $;$

2. a organização textual. Enquanto a fala possui uma organização baseada em princípios pragmáticos, a escrita se organiza logicamente e sintaticamente. Portanto a fala, principalmente a fala espontânea, se baseia em critérios ilocucionários e informacionais, desfrutando, para

\footnotetext{
${ }^{6} \mathrm{Na}$ verdade, o reconhecimento da especificidade e da independência das duas variações é uma aquisição relativamente recente entre os lingüistas; portanto, com maior razão, ela não pode ser pressuposta entre profissionais de outras áreas. Da rica bibliografia sobre a questão, limito-me a citar Halliday (1985) e Bruni e Raso (2002b).

${ }^{7}$ Não se ignora aqui a variabilidade ao longo do eixo diamésico e as diferenças entre tipologias de fala e de escrita, assim como tipologias de diamesias diferentes, como a rede, a televisão, o cinema, etc. Mas essa variabilidade não é pertinente ao objetivo didático em discussão, que é finalizado à conscientização dos efeitos do meio sobre o texto.

${ }^{8}$ Entre os inúmeros textos sobre anáfora e dêixis, vejam-se Levinson (1983), Conte (1999) e, em português, Koch (2004) e Koch; Morato; Bentes (2005).
} 
a manifestação da função comunicativa, a curva entonacional, as pausas, o tom da voz e uma rica série de marcadores discursivos. ' A escrita, ao contrário, precisa estruturar as informações segundo critérios lógicosintáticos, indispensáveis para que a mensagem seja recebida corretamente em ausência da entonação;

3. o léxico da fala é rico de palavras genéricas e de alta freqüência, de formas perifrásticas e de repetições. Isso é devido à rapidez com que a mensagem tem de ser elaborada e ao fato de que o silêncio, mesmo que de poucos segundos, gera conseqüências, normalmente indesejadas, no processo comunicativo. Mas já que o interlocutor tem pouquíssimo tempo para acompanhar o conteúdo do discurso, assim como o locutor para pronunciá-lo, e já que a entonação e os marcadores suprem a pobreza lexical e sintática, essas características são normalmente toleradas sem problemas na fala. A rapidez da comunicação oral, principalmente em gêneros textuais densos como os gêneros monológicos, necessita, e não só tolera, as repetições, já que uma quantidade muito grande das informações se perde na oralidade. Ao contrário, quem lê tem todo o tempo que quer para compreender o texto, assim como quem escreve para formulá-lo de maneira bem organizada e precisa. Portanto o leitor, que não pode contar com as informações presentes na entonação e não pode desfrutar ofeed-back, é inevitavelmente incomodado por um texto pouco claro ou pouco apropriado.

O primeiro passo para qualquer didática da escrita é tornar os aprendizes conscientes dessas diferenças e treiná-los para reconhecê-las e superá-las.

\footnotetext{
${ }^{9}$ Para aprofundar a dimensão que adquire o critério ilocucionário na fala veja-se a teoria da língua em ato elaborada em Cresti 2000 e aplicada às quatro principais línguas românicas em Cresti-Moneglia (2005). Para maiores detalhes e trabalhos específicos, vejam-se os textos presentes no site http://lablita.dit.unifi.it/. Não me parece que esse critério tenha sido considerado nas propostas de tipologias textuais. Entretanto, como Cresti e Moneglia mostram, é indubitável que ele mude a própria evidência, passando de tipologias orais mais dialógicas para tipologias mais monológicas, até tipologias em que a entonação exerça um papel muito específico, como nos locutores de futebol (ou de outros eventos) e na publicidade.
} 


\section{Exercícios}

Um exercício que, se realizado com a devida profundidade, tem-se mostrado excelente para esse objetivo é a reformulação de uma transcrição de um texto oral para realizar um texto que seja destinado a ser lido e não escutado, ou seja, um verdadeiro texto escrito. ${ }^{10}$ Nessa operação o formando enfrenta várias dificuldades:

1. em primeiro lugar, ele precisa compreender o texto, já que a transcrição não pode salvar todas as informações da execução falada, pois ele foi concebido para que fosse escutado. ${ }^{11}$ Esse é o primeiro momento em que o reformulador pode tomar consciência das distâncias que existem nas estratégias dos dois meios, principalmente se ele confrontar a facilidade de entender a execução falada com a dificuldade de compreender a transcrição;

2. em segundo lugar, ele precisa identificar e descrever as coordenadas situacionais que quem escuta possui, mas que quem lê não pode compartilhar: não é sempre óbvio e automático identificar os elementos que compõem essas coordenadas e reformulá-los, anaforicamente, para os novos objetivos. Muitas vezes, mesmo se, no início, a reformulação respeita o novo objetivo, ao longo do texto a tendência à infiltração dos elementos de oralidade pode se manifestar;

3. em terceiro lugar (também para o bom êxito da operação do ponto 2), ele precisa não tentar reformular o texto original acompanhando-o aos poucos, mas necessita fazer uma operação preliminar à reformulação: identificar e isolar as informações do texto original e anotá-las. Em caso contrário, o texto organizado para a fala vai condicionar o texto target, que vai ressentir em vários aspectos (relação com a situação, organização pragmática, léxico e estratégias lingüísticas) das suas características. Somente a partir das anotações vai ser possível desenvolver um novo texto, com objetivo diferente (ser lido e não escutado) e com as estratégias adequadas.

\footnotetext{
${ }^{10}$ Para um exemplo de exercício, com os êxitos de alguns alunos universitários, as correções e os fatores que as motivaram, veja-se Raso (2002b).

${ }^{11}$ Se perdem, portanto, as informações (riquíssimas) transmitidas pela prosódia e pela situação.
} 
Uma reformulação bem feita terá um número de palavras bem menor que o original e não mostrará traços da oralidade, nem na construção nem na formulação, mas conterá todas as informações originais.

\section{Gerenciar a documentação}

De fato, uma das operações mais importantes na redação de muitos textos, como uma tese acadêmica, um relatório, um projeto e outros, é a busca da documentação em textos diferentes, que, portanto, se tornam fontes. Freqüentemente as fontes que apresentam uma documentação útil usam-na para argumentar teses diferentes da nossa. Somente um olho treinado pode então identificar essas informações documentárias e separálas do contexto argumentativo em que ocorrem. As informações e os dados estatísticos, mesmo se muitas vezes apresentados como algo objetivo, não possuem valor argumentativo em si, mas podem ser utilizados para argumentar contra ou a favor de teses muito diferentes e até opostas. Por isso, a capacidade crítica de separar essas as informações do contexto argumentativo é algo que precisa ser treinado.

Confrontem-se, por exemplo, as duas formulações seguintes:

1. O risco país vai baixar desde que o governo liberalize o mercado do trabalho e reduza os impostos.

2. O risco país não vai baixar até quando o governo não liberalizar o mercado do trabalho e não reduzir os impostos.

A informação das duas formulações é idêntica, mas as duas possibilidades veiculam duas orientações argumentativas opostas. O caso 1 pode ser seguido por elogios ao governo, que parece ter alcançado um objetivo, enquanto o caso 2 , ao contrário, pode ser seguido por críticas ao governo, que parece não fazer o que é necessário. Isso significa que as duas formulações carregam pressuposições diferentes, ${ }^{12}$ que induzem os leitores a tirar conclusões que parecem, mas não são, comprovadas pelos fatos. De fato, em ambos os casos as informações que podem ser retiradas

${ }^{12}$ Sobre as pressuposições e a diferente natureza delas, existe uma bibliografia ampla, principalmente de natureza lógica. Os conceitos básicos (e suficientes, na nossa perspectiva), estão presentes em qualquer manual de semântica ou pragmática, como em Cançado (2005), Levinson (1983) ou Grundy (2000). 
são que a queda do risco país depende da liberalização do mercado de trabalho e da redução dos impostos. Nada se diz, mas muito se deixa entender, sobre a disponibilidade ou não do governo em tomar as providências. Isso significa que, em ambas as formulações, os textos que as contêm são fontes idênticas. Mas obviamente não é qualquer leitor que percebe isso. Um leitor não suficientemente treinado pode, portanto, ignorar a presença de uma informação importante para ele, simplesmente porque ela é presente no texto-fonte como uma pressuposição que pode induzilo a uma percepção incorreta.

\section{Exercícios}

Um exercício apropriado para isso é o que chamo de "resumo com mudança de corte". ${ }^{13}$ Nesse exercício um determinado texto (texto A) funciona como texto-fonte, e o aprendiz precisa escrever um texto bem menor (texto B), com um título diferente daquele do texto A, mas utilizando somente informações presentes ou pressupostas neste texto. O resumo com mudança de corte é um exercício que tem como objetivo desenvolver a capacidade do aprendiz em identificar a documentação de uma fonte sem confundi-la com a argumentação, explícita ou implícita, presente no texto.

Um exemplo disso pode ser o uso possível da informação de que nos EUA menos da metade da população vota nas eleições. Essa informação pode ser achada num texto que critica o sistema político dos EUA e a usa para argumentar que não se trata de uma verdadeira democracia, pois a maior parte da população não participa na tomada de decisões; mas pode ser utilizada também para escrever um novo texto que argumente que numa democracia madura as forças políticas e a população em geral alcançaram uma visão comum sobre os assuntos que mais costumam dividi-las ideologicamente e se diferenciam simplesmente quanto às propostas estratégicas para alcançar o mesmo objetivo.

Assim, por exemplo, um texto sobre as conseqüências que os relacionamentos extraconjugais tiveram na carreira política de Clinton e de outros políticos norte-americanos pode ser utilizado como fonte para um texto sobre a importância do movimento feminista nos Estados Unidos;

\footnotetext{
${ }^{13}$ Para um exemplo aprofundado de resumo com mudança de corte, com exercícios de alunos do ensino médio e de faculdade, e a correção comentada do formador, veja-se Raso (2002c).
} 
ou um texto sobre os propósitos de implementação infra-estrutural de um candidato a governador de um estado pode ser usado para descrever as infra-estruturas do mesmo estado no momento. Neste último caso, o título operaria uma transposição temporal: se no texto A o candidato manifestasse, por exemplo, a intenção de resolver o problema das comunicações entre a região norte e a região oeste do estado, no texto B essa informação pode levar a descrever as infra-estruturas atuais como carentes quanto à comunicação viária entre as duas regiões do estado.

Esse exercício apresenta grandes dificuldades para a maioria dos aprendizes:

1. em um primeiro momento eles precisam isolar as informações do texto-fonte;

2. em um segundo momento o aprendiz precisa esquecer o texto-fonte para selecionar as informações que podem ser úteis para o próprio texto, deixando que somente o novo título, e não mais texto A, o guie nessa escolha;

3. nesse ponto o aprendiz precisa hierarquizar as informações segundo o próprio objetivo e, finalmente, formulá-las.

Se o aprendiz tenta escrever aos poucos o texto B olhando constantemente para o texto A, a operação não terá possibilidade de sucesso, por várias razões: ele conseguirá talvez preservar a novidade do seu texto nas primeiras linhas, mas inevitavelmente será condicionado cada vez mais pelo texto-fonte. O resultado, se correto, terá necessariamente uma ordem das informações diferente do texto-fonte, já que o objetivo será diferente; por isso, também o gerenciamento das informações precisa ser feito sem se olhar mais para o texto originário. O texto A é somente um contenedor de material documentário; o princípio que guia a escolha e o uso desse material está no novo título, e não mais no texto-fonte.

Esse exercício, além de ensinar a identificar as informações dentro de um contexto argumentativo, ensina o gerenciamento dessas informações de uma maneira bem mais complexa do que aquela do primeiro exercício. Se na reformulação a partir do texto falado o aprendiz precisa muitas vezes mudar a ordem das informações para alcançar a ordem apropriada para um texto escrito, agora ele precisa fazer duas operações distintas: selecionar as informações úteis aos novos objetivos, em função do novo título, e hierarquizá-las de maneira correta segundo as exigências do próprio texto, 
trazendo às vezes, em primeiro plano, informações que estavam no fundo do outro texto e vice-versa.

Lembre-se também de que se trata de um resumo, já que o novo texto poderá inevitavelmente acolher somente uma parte, às vezes bem pequena, do texto-fonte. Por isso o exercício pode utilmente ser precedido por exercícios de resumos puros, em que se treina a capacidade de selecionar as informações com base na sua hierarquia. No resumo com mudança de corte o aprendiz precisará dessa habilidade, que deverá ser integrada com a capacidade de mudar o ponto de vista com que operar a hierarquização.

\section{Os gêneros textuais e a reformulação}

A reflexão sobre os gêneros textuais é um dos temas mais tradicionais da lingüística textual. ${ }^{14}$ Grande ressonância tem tido a proposta de Wehrlich (1975) de que existiriam cinco macro-tipos cognitivamente originários. ${ }^{15}$ Apesar de ainda ser usada, essa classificação não se baseia em nenhuma evidência científica. Mais recentemente, graças principalmente aos novos estudos de corpora, apareceram novas propostas de classificação tipológica, bem mais complexas, e fundamentadas em critérios textuais e de estatística fatorial. ${ }^{16}$ Lidar com um texto concreto não significa, evidentemente, lidar com prevalências de narrações ou descrições, mas com funções identificáveis na relação entre o conteúdo, a estruturação e os objetivos do texto por um lado, e, por outro lado, as expectativas induzidas por parâmetros textuais e lingüísticos nos quais o leitor identifica as características de um gênero: uma carta, um aviso, um projeto, uma poesia, um artigo acadêmico ou outros gêneros, e, mais especificamente, uma carta ao amigo, uma carta comercial, uma carta circular, uma carta de amor, etc.

Esses parâmetros são sinalizados através de traços muito concretos, como o tipo de divisão hierárquica do texto, a presença de alocuções, a emergência ou o ocultamento do $e u$, a presença de rimas, a densidade

\footnotetext{
${ }^{14}$ Por um quadro geral, vejam-se Mortara Garavelli (1988) e, mais recentemente, Heinemann e Viehweger (2000a; 2000b).

${ }^{15}$ Os tipos seriam: narrativo, argumentativo, descritivo, regulativo e informativo.

${ }^{16}$ Veja-se principalmente Biber (1988; 1995), que usa a lingüística textual, a estatística fatorial e a informática para identificar, no inglês e em outras línguas, os traços que, organizados em grupos, permitem a previsão de um gênero textual, caso os traços sejam em número estatisticamente relevante e caso os grupos sejam formados com critérios fatoriais e a probabilidade de co-ocorrência calculada informaticamente.
} 
lexical, a complexidade sintática, a proporção de nomes e verbos, o preenchimento dos nós argumentais dos verbos, e muitíssimos outros. ${ }^{17}$ Isso significa que a competência na elaboração dos gêneros textuais consiste na capacidade de gerenciar esses traços em relação às funções de cada texto. Assim, por exemplo, um micro-traço como o preenchimento rigoroso dos argumentos verbais é característico de um texto jurídico ou de um artigo científico, enquanto o contrário é característico de um texto poético, mas um tratamento intermediário seria típico da maioria dos tipos. Para identificar um gênero textual específico seria, portanto, necessário identificar a coocorrência de muitos traços.

Adquirir essa competência é um passo essencial para o escritor profissional. Ela pode ser desenvolvida quanto a gêneros diferentes, dependendo das necessidades didáticas de cada ordem de estudo e cada âmbito profissional, mas a consciência de que cada gênero textual obedece a regularidades fundamentadas na experiência e na expectativa dos leitores é comum a todos os níveis didáticos. Uma reflexão sobre os elementos pertinentes na construção textual é extremamente útil; ela pode ser acompanhada por vários exercícios de redação textual.

\section{Exercícios $^{18}$}

O exercício mais simples é de fornecer um objetivo comunicativo (ou seja, a ação que o texto deve executar ${ }^{19}$ ), um destinatário e um gênero

\footnotetext{
${ }^{17}$ Por uma tentativa interessante de tipologia textual baseada em um amplo número de traços e pautada pelo pacto comunicativo entre o autor e o leitor, veja-se Sabatini (1999).

${ }^{18}$ Alguns exemplos são aprofundados, com as correções comentadas, em Raso (2002d).

${ }^{19} \mathrm{~A}$ interpretação do objetivo comunicativo como ação evidencia a importância de uma formação pragmática para o formador. A teoria austiniana dos atos de fala (vejam-se ao menos AUSTIN, 1962 e SEARLE, 1969), assim como a teoria griceana das implicaturas (GRICE, 1975) não podem faltar na bagagem de um bom formador. Um ótimo manual de pragmática é Levinson (1983), integrável com Grundy (2000), que inclui um importante capítulo sobre politeness. No âmbito da teoria da Nova Retórica, são interessantes as reflexões de Miller (1994), que insiste na visão do gênero como ação social em um espaço mediador entre o micro-nível do processamento da linguagem natural e o macro-nível da cultura. Trata-se de uma reflexão prevalentemente retórica e pouco lingüística, mas importante e facilmente integrável através de uma bibliografia diferente, como a da escola de Sidney, de matriz hallidayana (EGGINS; MARTIN, 1997) e outras. O objetivo é integrar as capacidades de dedução contextual e de governo da situação com a necessidade de conhecer os registros como conjunto de traços co-ocorrentes que permitem a predição textual.
} 
textual definido, ${ }^{20}$ estabelecendo em que condição o autor do texto precisa se manifestar. Por exemplo, o aprendiz deveria escrever, na condição de síndico de um condomínio, uma carta para os condôminos em que relata um certo tipo de gasto a ser feito, as razões, os prazos e os efeitos sobre a taxa condominial; ou escrever um aviso, como funcionário do Detran, informando sobre determinados problemas de funcionamento da estrutura em certos dias; ou um currículo vitae a ser enviado a uma empresa; ou a ata de uma reunião de condomínio anteriormente gravada e escutada; ou infinitas outras possibilidades. Esse exercício concentra a atenção sobre os traços que definem os vários tipos: uma carta, por exemplo, é caracterizada pela presença de uma data e do lugar, pelo alocutivo com um título (por ex. Caro dr. Queiroz), pela presença de uma fórmula de despedida, etc.

Um exercício mais difícil é reformular um texto que já existe, variando o destinatário. Um bom exemplo é reformular um verbete de uma enciclopédia para um livro de texto do primeiro ou segundo ciclo do ensino fundamental. Isso implica decidir como simplificar o texto e a linguagem, provavelmente quais partes eliminar e quais ampliar, como parafrasear a linguagem científica, como introduzir imagens, como hierarquizar o texto, por exemplo, dividindo-o em parágrafos, etc. Uma outra possibilidade é, a partir de uma carta em que se conta um acidente de carro para um amigo, reformulá-la, escolhendo como novo destinatário a própria companhia de seguro. Esse tipo de exercício permite a reflexão sobre os conceitos de destinatário e de registro lingüístico. Por exemplo, mudando o destinatário da carta não vai ser possível manter os mesmos alocutivos ou as mesmas formas para se referir a si mesmo; será necessário usar um registro mais formal e descrever o acidente com maior precisão; a fórmula de despedida terá de ser outra; dentro da carta terá de aparecer o próprio endereço, a referência à própria posição como segurado, etc.

Nesse exercício se aprofunda o conceito de gênero textual, mostrando como ele não é sensível somente ao conteúdo, mas à função comunicativa e ao contexto: uma carta pode "contar" algo para que o destinatário seja simplesmente informado de uma novidade ou pode fazê-lo para que ele

\footnotetext{
${ }^{20}$ Para a escolha de um gênero e para que os aprendizes saibam como ele pode ser reconhecido e gerenciado, é útil, entre outras, a reflexão de Swales (1990) sobre o conceito de Comunidade Discursiva. Essa reflexão é retomada e utilizada em várias obras sucessivas do mesmo autor (veja-se, mais recentemente, SWALES, 2004).
} 
cumpra uma ação clara, como aquela de uma companhia de seguro depois que um acidente for notificado. A explicação de um processo fisiológico como, por exemplo, a fonação, será organizada de maneira muito diferente se for parte de uma enciclopédia ou de um livro-texto, e neste caso será diferente, dependendo dos destinatários do texto (universidade, ensino médio, etc.).

Um terceiro passo será um exercício de correção de textos mal estruturados: por exemplo, um aviso ao público mal formulado, com texto demais, que o torna pouco legível, ou incapaz de selecionar o próprio destinatário (gerando efeitos contra-producentes, atraindo os leitores errados e não capturando a atenção dos verdadeiros destinatários) ou com uma hierarquia das informações errada (por exemplo, porque a informação principal é escondida no meio de informações menos relevantes ou até inúteis, ou porque a informação que precisa atrair imediatamente a atenção de um leitor que está passando é pequena ou não evidenciada com um corpo maior ou com um caráter que atribua evidência). Esse exercício pressupõe o conhecimento dos traços textuais que caracterizam um gênero textual (objetivo do primeiro tipo de exercícios) e pressupõe uma reflexão sobre como um gênero textual interage com o próprio contexto (objetivo do segundo tipo de exercícios). Ele também permite a discussão sobre a seleção das informações (quais são relevantes e quais não, dado um contexto específico), sobre a hierarquização das informações (quais precisam aparecer antes e porquê, quais precisam ser imediatamente visíveis e porquê, se a presença de um assunto ou de um título, dependendo do texto, pode exercer uma função de guia para o leitor e como esse elemento textual deve ser formulado para ser eficaz), sobre a construção sintática e lexical, dado um determinado registro ligado à situação.

\section{A situação comunicativa}

Esse quarto estágio tem o objetivo de integrar as competências dos estágios anteriores, através da elaboração e redação de vários textos a partir de um evento desencadeador comum, mas cada texto será condicionado por variáveis próprias. Nessa fase o aprendiz precisa aprender a lidar com todos os aspectos de uma situação comunicativa ao mesmo tempo, organizando uma verdadeira estratégia comunicativa: escolha do gênero para cumprir uma ação específica; reflexão sobre o destinatário de cada texto; identificação do objetivo comunicativo que um dado texto possui 
com relação a cada destinatário determinado, e que muda mesmo se o contexto geral é o mesmo; seleção das informações com base em cada objetivo comunicativo específico; hierarquização das informações com base em cada objetivo comunicativo e em cada gênero textual; formulação lingüística. Tudo isso colabora para alcançar um objetivo complexo com sucesso, que envolve várias ações coincidentes com operações textuais distintas.

\section{Exercicios $^{21}$}

Um exemplo: em 15 de março uma enchente atinge dois pequenos municípios (M1 e M2) situados a 20 quilômetros da capital (C). Muitas estruturas são destruídas, entre elas as duas agências do Banco do Brasil. O governador do estado dispõe, na periferia da capital, duas estruturas provisórias para o funcionamento das duas agências; elas serão operativas a partir de 23 de março. Um acordo com a Caixa Federal de M1 e M2 permite momentaneamente aos clientes do Banco do Brasil sacar dinheiro nessas duas agências da Caixa até um máximo de mil reais.

O aprendiz, na condição de gerente estadual do Banco do Brasil, precisa comunicar: 1. aos funcionários do Banco do Brasil de M1 e M2 que, a partir do dia 23 de março, serão destinados às novas estruturas e terão um benefício econômico de 20 reais por dia de trabalho por todo o tempo que for necessário; 2. aos clientes de M1 e M2 que, a partir de 23 de março, as agências das quais são clientes estarão num novo endereço e que, por enquanto, eles podem sacar até mil reais nas agências locais da Caixa; 3. aos funcionários de todas as agências do país que as duas agências de M1 e M2 estarão localizadas temporariamente em outro endereço.

Esse exercício pressupõe várias operações comunicativas, mesmo se todas geradas a partir de um evento comum. Para cada operação o formando precisa:

1. escolher os gêneros textuais apropriados: provavelmente, um telegrama para avisar os funcionários das duas agências, um aviso ao público para informar a população e a clientela de M1 e M2, uma carta para informar com menor rapidez, mas maior certeza e detalhes, a clientela de M1 e M2; um rápido e-mail e uma carta circular para informar as outras agências do Banco;

${ }^{21}$ Para exemplos de exercícios concretos com correção e comentário, veja-se Raso (2002e). 
2. decidir quais informações são apropriadas em cada texto: provavelmente não é necessário explicar a causa do desastre para os habitantes de M1 e M2, mas deve-se informá-los sobre como efetuar as operações bancárias de que eles precisam; somente as informações estritamente e imediatamente necessárias estarão no aviso, enquanto a carta disponibilizará maiores detalhes. Provavelmente a informação do benefício salarial entrará unicamente no telegrama aos funcionários e não nos outros textos. Provavelmente o e-mail e a carta para as outras agências conterão informações operacionais do Banco ausentes nos outros textos, que o autor dos textos não pode conhecer em detalhes mas pode prever em um hipotético anexo. Além dessas mais óbvias, outras informações completarão cada texto.

É evidente que um exercício como esse necessita ao mesmo tempo de muitas habilidades, em grande parte ligadas à capacidade de avaliar cada situação comunicativa concreta que envolve um texto. Não é mais suficiente conhecer os traços textuais que caracterizam uma carta, um aviso ou um telegrama, mas se tornam necessárias a competência para decidir quais gêneros textuais são mais apropriados para cada ato comunicativo e a competência em selecionar, dada uma situação, as informações para cada texto determinado. Somente depois dessas operações o formando deverá se preocupar em hierarquizar as informações, considerando os objetivos e as características de cada texto, e finalmente formulá-las lingüisticamente.

\section{A argumentação}

A argumentação ${ }^{22}$ é normalmente considerada uma das mais difíceis atividades textuais. Por isso ela precisa pelo menos das competências das primeiras duas fases, mas poderá ser beneficiada também pelo desenvolvimento das outras duas. Trata-se de uma atividade que, de maneira mais ou menos explícita, é necessária na elaboração de muitos textos diferentes: um texto acadêmico, um projeto, um relatório, etc. Freqüentemente a argumentação é combinada, e às vezes é confundida, com duas outras atividades: a documentação e a exemplificação. Enquanto a documentação não possui em si um valor conceitual, mas oferece dados

\footnotetext{
${ }^{22}$ Sobre a argumentação, vejam-se Perelman-Olbrechts; Tyteca (1958); para um ótimo exemplo de didática da argumentação, veja-se Dell'Aversano-Grilli (2006).
} 
potencialmente universais que depois deverão ser interpretados, a exemplificação possui um valor conceitual, mas esse valor é limitado a um caso específico da experiência. Nenhuma dessas duas operações, documentar e exemplificar, pode, portanto, substituir a argumentação, que tem como objetivo convencer conceitualmente da validade de uma tese, independentemente de experiências concretas. Todavia, documentação e exemplificação podem utilmente ajudar na elaboração de um texto argumentativo.

Uma boa atividade argumentativa precisa da competência no uso da documentação, desenvolvida autonomamente no segundo estágio do processo formativo, mas precisa também de um domínio da situação comunicativa, desenvolvida no quarto estágio, e, enquanto concretamente colocada num determinado gênero textual, precisa das competências do terceiro estágio. Cada atividade argumentativa concreta está colocada numa situação comunicativa, dentro das quais os argumentos, os dados e as exemplificações precisam ser avaliados.

\section{Exercícios}

Um treinamento da argumentação pode ser organizado em três fases: ${ }^{23}$

a) a primeira, que pode acontecer em qualquer momento depois do primeiro estágio formativo, consiste na construção de um texto argumentativo sem documentação. Nessa fase a atividade argumentativa, livre de qualquer outro vínculo, pode utilmente ser exercitada justamente para que o formando aprenda claramente a distingui-la da documentação e, sobre tudo, da exemplificação. Não é raro, de fato, que, inicialmente, para sustentar uma tese, a tendência seja de fornecer exemplos de casos concretos a favor da posição que se quer apoiar. Nessa primeira abordagem, a atividade argumentativa pode-se pedir ao formando que forneça um número definido de argumentos a favor ou contra uma tese dada, dentro de um texto que prevê uma introdução e uma conclusão funcionais ao aproveitamento dos argumentos. É útil repetir o exercício com a tese contrária, pois o objetivo não deve ser argumentar a favor de uma tese na qual se acredita, mas uma operação técnica. Inclusive, explorar os argumentos contrários ajuda a construir confutações desses

${ }^{23}$ Para um aprofundamento dos exercícios e sobre a correção comentada de exercícios de alunos do ensino médio e do ensino superior, veja-se Raso (2002f). 
argumentos, ou seja, a elaborar melhores argumentos a favor. No caso de o aprendiz acreditar na tese, argumentar o contrário vai induzi-lo a ver o lado dos hipotéticos adversários e a considerar as razões deles; o inverso acontecerá se ele não acreditar na tese. Em ambos os casos a operação o levará a avaliar a complexidade de um debate, além do próprio ponto de vista imediato, e a reconsiderar e re-elaborar os argumentos. Nessa fase é importante, através do brain storming, recolher todos os argumentos disponíveis antes de escolhê-los e hierarquizá-los, pensando que a posição dos argumentos deve ser do mais fraco ao mais forte, pois se os primeiros argumentos não alcançarem o objetivo, os outros ainda podem ter a chance de alcançá-lo;

b) a segunda fase consiste em introduzir, em graus variáveis, fontes que precisam ser utilizadas documentariamente. Dependendo dos objetivos, as fontes podem ser de natureza estatística, literária, ou de outra natureza, e podem pressupor atividades textuais preliminares diversas, como um resumo, um fichamento, as corretas técnicas de citação, de construção de notas de rodapé ou uma bibliografia. Por exemplo: uma fonte poderia ser um texto a ser inserido sob forma de resumo como documentação na unidade textual de um dos argumentos; outra fonte pode gerar uma citação dentro de outra unidade; outra ainda pode ser o fichamento feito anteriormente a partir de outros textos; o fichamento disponibilizaria assim muitas informações, algumas das quais o aprendiz, na hora da elaboração do texto, escolheria para ser utilizada como documentação. Uma fonte pode ser, ainda, destinada à construção de uma nota de rodapé; outras podem pressupor quaisquer atividades textuais diferentes. Isso permite a integração entre atividades textuais isoladas e uma atividade textual complexa: como se utiliza um resumo dentro de um texto mais amplo, como se realiza corretamente uma citação, como se faz e se usa um fichamento, como se hierarquiza a informação entre texto e notas. Pode-se exigir também que cada unidade argumentativa seja integrada por uma utilização do material documentário e por uma exemplificação. Em princípio, a acumulação de dificuldades que tornem a operação mais complexa e que pressuponham atividades preliminares é ilimitada, e pode ser graduada e escolhida segundo o nível e os objetivos formativos. As fontes podem também ser utilizadas para que sejam citadas em notas, exercitando, assim, a capacidade do formando de gerenciar a hierarquia do texto dentro dos dois níveis do texto e das notas. Pode-se também 
pedir uma bibliografia final das várias fontes utilizadas, o que evidentemente é funcional à argumentação com finalidades acadêmicas. Naturalmente, essas operações pressupõem que nas fases anteriores sejam construídas as competências requeridas;

c) a terceira fase consiste em pedir que se argumente a favor ou contra uma determinada tese para um público definido, com base em características que o tornem sensível a determinados argumentos e não a outros. Por exemplo, argumentar a favor da liberdade da mulher pode ser muito diferente se o público for um grupo de aprendizes da faculdade de sociologia ou um grupo de imigrantes muçulmanos na Alemanha. A escolha dos argumentos nessa fase pressupõe a reflexão sobre como um destinatário concreto, com sua ideologia, sua experiência e sua visão de mundo reagirá a eles, ou seja, pressupõe uma atividade importantíssima e muito difícil: olhar o texto com olhos diferentes dos próprios. ${ }^{24}$

\section{Conclusão}

Essas cinco etapas, expostas aqui de maneira muito sintética, ${ }^{25}$ constituem uma proposta coerente para um núcleo duro de competências que um bom formador em escrita profissional deve possuir. Elas não podem, portanto, faltar em qualquer curso de formação de formadores. Naturalmente essas competências, como já se disse, não completam o perfil de um formador. Os limites são de dois tipos: um primeiro limite está no fato de que as operações textuais aqui discutidas, com exceção da primeira, necessitam de competências preliminares; todavia essas competências podem ser consideradas próprias de uma formação elementar em relação à escrita (como o resumo ou a paráfrase) e, portanto pressupostas em qualquer formador, ou típicas de gêneros específicos (como a citação, o gerenciamento das notas de rodapé ou a bibliografia). A formação de formadores pode ser considerada uma fase avançada na formação para a escrita, mas nada impede que sejam retomadas e aprofundadas habilidades textuais como o

${ }^{24}$ Essa capacidade é importantíssima também na atividade de revisão do texto, para a qual não temos o espaço aqui para falar, mas sobre a qual recomendamos Gernsbacher e Traxler (1995), que relacionam a atividade da revisão ao conceito de coerência textual (sobre esse conceito veja-se, também, pelo menos Conte (1999).

${ }^{25}$ A bibliografia fornece os instrumentos para aprofundar cada uma das etapas. 
resumo, que então precederá a segunda etapa, ou a paráfrase, que terá um espaço antes da terceira, assim como outras habilidades.

Dois vínculos não podem faltar em todas as fases: os limites de tempo e de número de palavras. Quanto ao tempo, escrever profissionalmente significa gerenciar tarefas dentro de um tempo que tem um valor econômico; não importa o texto de um projeto ter ficado excelente, quando quem o comissionou não pôde ou não quis esperar e preferiu o texto de um concorrente; ou que os textos para gerenciar a situação causada por um evento imprevisto sejam perfeitos, se chegam quando as conseqüências do evento já os tornaram obsoletos. O que conta na escrita profissional não é produzir o melhor texto, mas produzir o melhor texto possível dentro das circunstâncias dadas. O aprendiz, portanto, precisa aprender a considerar essas circunstâncias como mais importantes do que o texto em si, e adquirir a capacidade de olhar para o texto em termos relativos, superando o medo, muito freqüente, de expor o próprio ego através de um produto inevitavelmente imperfeito. $\mathrm{O}$ aprendiz não pode em caso nenhum achar que o próprio campo de visão se limita ao texto que está escrevendo. Pelo contrário, essa é exatamente a pior atitude possível para um escritor profissional, e toda a atividade de formação deve educar o futuro escritor profissional (e ainda mais o futuro formador) a perceber a própria atividade como interna a uma engrenagem maior que ele. O escritor profissional não pode, portanto, se dar ao luxo de perder a conexão com essa engrenagem, pois isso coincidiria com a perda da própria função.

Quanto ao número de palavras, sabemos que raramente num meio profissional o espaço é ilimitado. O importante então será utilizá-lo da melhor maneira possível; reclamar porque o espaço, assim como o tempo, é reduzido demais, não vai trazer nenhuma vantagem. A limitação de espaço implementa assim habilidades fundamentais, como a de selecionar as informações, e induz à busca de recursos variados para hierarquizá-las. Em certos gêneros textuais, como o aviso ao público, a redução de palavras adquire em si uma vantagem comunicativa, permitindo desfrutar melhor o espaço físico ou de tempo para alcançar o destinatário. Mas esse é o caso também de gêneros que usam menos artifícios gráficos, como os informativos de produtos e até as cartas de trabalho, que podem, se longos, desencorajar o leitor e acabar na lixeira antes de serem lidos; ou como no trabalho de um ghost-writer, que precisa tornar o mais proveitoso possível o tempo da autoridade que será o autor aparente do texto. 
Combinados um com o outro, e também combinados com outros vínculos, os limites de espaço e de tempo obrigam o autor a desenvolver uma habilidade essencial em qualquer produção textual: projetar. Como já foi dito indiretamente a propósito das operações textuais das cinco etapas, não é possível construir um texto equilibrado e completo, e menos ainda governando vários vínculos, sem uma fase de projeção prévia. Construir textos não é uma atividade cognitivamente linear, mas, sim, uma atividade hierarquizada, que prevê operações ordenadas sucessivamente para gerar um produto compósito que, a partir da individualização de um objetivo comunicativo, leve o aprendiz a reflitir sobre as estratégias apropriadas para alcançá-lo, recolher as idéias e as informações necessárias, ordená-las e, somente depois, formulá-las lingüisticamente. ${ }^{26}$ A projeção é, portanto, uma habilidade que acompanha todas as etapas da formação dos formadores, que é pensada também para desenvolver essa habilidade nas suas diferentes realizações e com um nível crescente de complexidade.

\section{Referências}

ACERBONI, G. Progettare e scrivere per Internet. Milano: McGraw-Hill, 2005. AUSTIN, J. L. How to do things with words. London: Oxford University Press, 1962.

BARR, R.; KAMIL, M. L.; MOSENTHAL, P. B.; PEARSON, P. D. (Org.). Hanbook of Reading Research. New York; London: Longman, 1991. v. II.

BEREITER, C.; SCARDAMALIA, M. The Psycology of Written Composition. Hillsdale, NJ: Lawrence Erlbaum, 1987.

BIBER, D. Variation across Speech and Writing. Cambridge: Cambridge University Press, 1988.

BIBER, D. Dimensions of register variation. A cross-linguistic comparison. Cambridge: Cambridge University Press, 1995

\footnotetext{
${ }^{26}$ A investigação dos aspectos cognitivos da escrita gerou uma bibliografia muito ampla. Quem queira ter um quadro completo dela pode consultar os números das revistas Text e, especialmente, Discourse Processes. Aqui limito-me a indicar Barr; Kamil; Mosenthal; Pearson (1991), todo dedicado aos mecanismos cognitivos da leitura; Gregg; Steimberg (1980), em que é publicado Hayes e Flowers (1980) que deram o primeiro grande impulso ao estudo dos mecanismos cognitivos da escrita e que, dezesseis anos depois, foi reformulado e integrado por Hayes (1996); Bereiter; Scardamalia (1987).
} 
BRUNI, F. et alii. Manuale di scrittura e comunicazione. Bologna: Zanichelli, 1997a.

BRUNI, F. et alii. Manuale di scrittura professionale. Bologna: Zanichelli, 1997b.

BRUNI, F.; RASO, T. (Org.). Manuale dell'italiano professionale. Bologna: Zanichelli, 2002a.

BRUNI, F.; RASO, T. La situazione comunicativa tra scritto e parlato. In: (Org.). Manuale dell'italiano professionale. Bologna: Zanichelli, 2002b. p. 3-12.

CANÇADO, M. Manual de semântica. Belo Horizonte: Editora UFMG, 2005.

CONTE, M. E. Condizioni di coerenza. Ricerche di linguistica testuale (Nova edição com dois novos ensaios, org. por B. Mortara Garavelli). Alessandria: Edizioni dell'Orso, 1999.

COVINO, S. (Org.). La scrittura professionale. Ricerca, prassi, insegnamento (Atti del I Convegno di studi. Perugia, Università per Stranieri, 23-25 Ottobre 2000). Firenze: Olschki, 2001.

CRESTI, E. Definizione dell'enunciato e pragmatica. In: BRASCA, L.; ZAMBELLI, L.M. (Org.). Atti del V Convegno nazionale GISCEL. Grammatica del parlare e dell'ascoltare a scuola. Firenze: La Nuova Itália, 1992. p. 51-77.

Speech act units and informational units. Em: FAVA, E. Speech Acts and Linguistic Research. Proceedings of the Workshop, July 15-17, 1994. Buffalo: Center for Cognitive Science - Padova: Nemo, 1995. p. 89-107.

. Corpus di italiano parlato. Firenze: Accademia della Crusca. 2000, 2 voll. + CDRom.

Illocuzione e modalità. Em: BECCARIA, P.; MARELLO, C. (Org.). La parola al testo. Scritti per Bice Mortara-Garavelli. Alessandria: Ed. dell'Orso, 2001a. p. 133-145.

. Per una nuova definizione di frase. Em: BONGRALLI, P.; DARDI, A.; FANFANI, M., TESI, R. (Org.). Studi di storia della lingua italiana offerti a Ghino Ghinassi. Firenze: Le Lettere, 2001b. p. 511-550.

Enunciato e frase: teoria e verifiche empiriche. Em: BIFFI, M.; CALABRESE, O.; SALIBRA, L. (Org.). Italia Linguistica: discorsi di scritto e di parlato. Scritti in onore di Giovanni Nencioni. Siena: Prolagon, 2005. p. 249-260.

Illocution et modalité dans le comment e le topic. Em: SCARANO, A. (Org.). Macro-syntaxe et pragmatique. L'analyse linguistique de l' oral. Roma: Bulzoni, 2003. p. 133-182. 
CRESTI, E.; MONEGLIA, M. (Org.). C-ORAL-ROM. Integrated Reference Corpora for Spoken Romance Languages. Amsterdam-New York: Johns Benjamins, 2005. + DVD.

DELL'AVERSANO, C.; GRILLI, A. La scrittura argomentativa. Dal saggio breve alla tesi di dottorato. Firenze: Le Monnier, 2005.

EGGINS, S.; MARTIN, J. R. Genres and registers of discourse. In: VAN DIJK, T. A. (Org.). Discourse as structure and process. London: SAGE Publications, 1997. p. 231-291.

GERNSBACHER, M.; TRAXLER, J. Improving Coherence in Written Communication. In: GERNSBACHER, M. A.; GIVÒN, T. (Org.). Coberence in Spontaneous Texts. Amsterdam-Philadelphia: Johns Benjamins, 1995. p. 215-238.

GREGG, L. W.; STEIMBERG, E. R. (Org.). Cognitive Processes in Writing. Hillsdale (NJ): Lawrence Erlbaum Associates, 1980.

GRUNDY, P. Doing Pragmatics. Lodon: Arnold, 2000.

HAJES, J. R. A New Framework for Understanding Cognition and Affect in Writing. In: LEVY, C. M.; RANSDELL, S. (Org.). The Science of Writing. Theories, Methods, Individual Differencies and Applications. Mahwa (NJ): Lawrence Erlbaum, 1996.

HAJES, J. R.; FLOWERS, L. S. Identifying the Organisation of Writing Processes. In: GREGG; Steimberg, 1989, p. 3-30.

HALLIDAY, M. A. K. Spoken and Written Language. Victoria: Deakin University Press, 1985.

HEINEMANN, W.; VIEHWEGER, D. Typologisierung von Texten I: Kriterien, Textsorte, Textmuster, Texttyp. In: BRINKER, K.; ANTOS, G; HEINEMANN, W.; SAGER, S. F. (Org.). Handbücher zur Sprach-und Kommunikationwissenschaft: Text-und Gesprächlinguistik. Berlin-New York: Walter de Gruyter, p. 507-523.

Typologisierung von Texten I: Kriterien, Aspekte der Textsortendifferenzierung. In: In: BRINKER, K.; ANTOS, G; HEINEMANN, W.; SAGER, S. F. (Org.). Handbücher zur Sprach- und Kommunikationwissenschaft: Text-und Gesprächlinguistik. Berlin-New York: Walter de Gruyter, p. 523-546.

KOCH, I. G. V. Introdução à Lingüistica Textual: trajetória e grandes temas. São Paulo: Martins Fontes, 2004.

KOCH, I. G. V.; MORATO, E. M.; BENTES, A. C. Referenciação e Discurso. São Paulo: Contexto, 2005.

LEVINSON, S. S. Levinson. Pragmatics. Cambridge: Cambridge University Press, 1983. 
MILLER, C. R. Genres as social action. In: FREEDMAN, A; MEDWAY, P. (Org.). Genres and new rhetoric. London: Taylor \& Francis, 1994. p. 67-78.

MORTARA GARAVELLI, B. Text Typologie. Em: HOLTUS, G.; METZELTIN, M.; SCHMITT, C. (Org.). Lexicon der Romanistischen Linguistik. Band IV. Tübingen: Niemeyer, 1988. p. 157-168.

PERELMAN, C.; OLBRECHTS TYTECA, L. Traité de l'argumentation: la nouvelle rhétorique. Paris: Presses Universitaires des France, 1958.

RASO, T. Origini e strategie dell'informazione in alcune testualità burocratiche. Studi linguistici italiani, n. 25, p. 234-266, 1999. n. 26, p. 97-129, 2000. $2002 \mathrm{~b}$. La gestione dell'informazione. In: BRUNI-RASO, 2002a, p. 63-71,

Riformulare dal parlato allo scritto. BRUNI, F.; RASO, T. (Org.). 2002a, p. 201-207, 2002c.

Il riassunto con cambio di taglio. In: BRUNI, F.; RASO, T. (Org.). 2002a, p. 210-222, 2002d.

La situazione comunicativa. In: BRUNI, F.; RASO, T. (Org.). 2002a, p. 223-248, 2002e.

Altri tipi testuali: un avviso al pubblico, una richiesta di finanziamento e una voce di enciclopedia. In: BRUNI, F.; RASO, T. (Org.). 2002a, p. 277-286, $2002 \mathrm{f}$. $323,2002 \mathrm{~g}$

I testi argomentativi. In: BRUNI, F.; RASO, T. (Org.). 2002a, p. 287-

(Org.). Corso di scrittura professionale per gli uffici e per la Pubblica Amministrazione. Pisa: ICoN (www.italicon.it), 2004.

La scrittura burocratica. La lingua e l'organizzazione del testo. Roma: Carocci, 2005.

SABATINI, F. "Rigidità-esplicitezza" vs. "elasticità-implicitezza": possibili parametri massimi per una tipologia dei testi. In: SKYTTE, G.; SABATINI, F. (Org.). Linguistica Testuale Comparata. Copenhagen: Museum Tusculanum Press, 1999. p. 141-172.

SEARLE, J. Speech Acts. An essay in the philosophy of language. Cambridge: Cambridge University Press, 1969.

SWALES, J. M. Genres analysis: English in academic and research settings. Cambridge: University Press, 1990.

SWALES, J. M. Research genres: explorations and applications. Cambridge: University Press, 2004.

WEHRLICH, E. Typologie der Texte. Etwurfeines textlinguistischen Modells zur Grundlengung einer Textgrammatik. Heidelberg: Quelle \& Meyer, 1975. 